\title{
Cardiac paraganglioma
}

\author{
Derrick Y. Tam MD, Robert James Cusimano MSc MD
}

- Cite as: CMAJ 2017 July 31;189:E996. doi: 10.1503/cmaj.170067

A 25-year-old woman with a history of anemia and anxiety presented to her hematologist with palpitations. An echocardiogram was ordered, which showed a right ventricle mass measuring $5.4 \mathrm{~cm}$ $\times 6.4 \mathrm{~cm}$. She was referred to cardiology for further work-up. A computed tomography (CT) scan showed that the lesion was typical for a paraganglioma, arising in the atrioventricular groove (Figure 1A). An octreotide scan with Indium-111 showed positive uptake of the radioactive tracer isolated to the cardiac mass. Ten-fold elevation of the urinary catecholamine metabolites (dopamine, norepinephrine and normetanephrine) led to a diagnosis of a functional cardiac paraganglioma. At coronary catheterization, contrast injected into the right coronary artery highlighted the rich vascularity of the mass (a video [Appendix 1] and an image [Appendix 2] are available at www.cmaj.ca/lookup/ suppl/doi:10.1503/cmaj.170067/-/DC1). Intraoperatively (Figure $1 B)$, a hypervascular tumour in the atrioventricular groove was resected en bloc with partial reconstruction of the atrium and saphenous vein bypass of the right coronary artery. The tumour had not invaded the myocardium of the right ventricle. The patient was discharged from hospital 12 days postoperatively and was free of symptoms at one-month follow-up.

Paragangliomas are chromaffin tumours arising from parasympathetic or sympathetic ganglia neural crest cells that are outside of the adrenal gland. ${ }^{1}$ The incidence of paragangliomas is between 1.5 and 9 cases per million people. Cardiac paragangliomas make up $2 \%$ of all paragangliomas. ${ }^{2}$ Although most paragangliomas occur sporadically, recent evidence suggests that up to a third may be familial, highlighting the importance of screening immediate family. 1,3 Paragangliomas most often occur around the fourth decade of life, and present with hypertension or palpitations with a mass found on echocardiography. CT and/or magnetic resonance imaging can provide further anatomic and tissue characterization, and laboratory investigations (urine and blood) for catecholamines and metabolites are required to assess functionality. ${ }^{1}$ These tumours are well vascularized (Figure $1 \mathrm{~B}$ and Appendix 2) and should not be biopsied, as this may result in life-threatening hemorrhage. Referral to a cardiac surgical centre with expertise in cardiac tumours can be life-saving. Definitive management of cardiac paraganglioma is surgical and requires excision with clear margins. Up to $10 \%$ of cardiac paragangliomas are malignant, but early complete surgical resection with negative margins can result in a full cure. ${ }^{1}$

\section{References}

1. Joynt KE, Moslehi JJ, Baughman KL. Paragangliomas. Cardiol Rev 2009;17:159-64.

2. Ramlawi B, David EA, Kim MP, et al. Contemporary surgical management of cardiac paragangliomas. Ann Thorac Surg 2012;93:1972-6.

3. Martucci VL, Emaminia A, del Rivero J, et al. Succinate dehydrogenase gene mutations in cardiac paragangliomas. Am J Cardiol 2015;115:1753-9.

\section{Competing interests: None declared.}

This article has been peer reviewed.

The authors have obtained patient consent.

Affiliation: Peter Munk Cardiac Centre, Division of Cardiac Surgery, University Health Network, University of Toronto, Toronto, Ont.

Correspondence to: Robert Cusimano, Robert.cusimano@uhn.ca

A video of coronary catheterization in a 25 -year-old woman with a functional cardiac paraganglioma is available in Appendix 1, at www.cmaj.ca/lookup/suppl/doi:10.1503/ cmaj.170067/-/DC1 